\title{
Tooth Mineralization: A Technical Note on the Moorrees-Fanning-Hunt Standards
}

\author{
Edward F. Harris ${ }^{1}$ and Andrea L. Buck ${ }^{2}$ \\ ${ }^{1}$ Department of Orthodontics, College of Dentistry, University of Tennessee, Memphis, Tennessee 38163 \\ ${ }^{2}$ Osteological Research Consutling Associates, Phoenix, Arizona 85048
}

ABSTRACT One of the largest, longitudinal studies of tooth mineralization is that described by Moorrees, Fanning and Hunt (J Dent Res, 1963) based on children growing up in Boston, Massachusetts, and Yellow Springs, Ohio. This short communication provides

Tooth formation proceeds in a highly regimented fashion, and the developmental status of formative teeth can be used to assess a child's dental age, which is one measure of his degree of biological maturity. Tanner et al. (1975) comment that, "Maturity differs in an important way from a measurement such as stature, in that the normal growth process takes every individual from one common condition of being wholly immature to another of being wholly mature." Various tissue systems have been used to determine biological age; the most common techniques depend either on formation of the teeth (so-called dental age), the morphological development of a set of bones, notably those in the hand and wrist (bone age), and the onset of secondary sexual characteristics (pubertal age; Marshall et al., 1969, 1970). Dental and bone ages have the advantage that their applicability extends over much of a person's growth span from fetal life through late adolescence.

Formation of the teeth is useful for a variety of reasons. The degree of crown-root formation can be viewed directly on skeletal material (both recent and archeological; Owsley and Jantz, 1983; Conroy and Vannier, 1987; Liversidge, 2000) and analogously on living subjects (e.g., Crossner and Mansfield, 1983. Tooth formation spans almost two decades when the primary and permanent teeth are combined along with the variable third molars (Harris, 2002). Additionally, tooth formation appears to be under substantial genetic control (Pelsmaekers et al., 1997; Merwin and Harris, 1998) - more so than bone age (e.g., Garn et al., 1965; Keller et al., 1970).

Moorrees, Fanning and Hunt (MFH) published the first standards for tooth formation derived from a large series of children followed longitudinally. Longitudinal data are requisite to identify the timing of onset of a stage (Smith, 1991). The MFH standards have been applied broadly and still are commonly cited despite their narrow ethnic base (Americans of western European extraction) and the possibility of secular effects speeding up the tempo of tooth formation since the MFH data were collected beginning tables of the means and standard deviations, by sex, in order to make the data more accessible and usable than the graphic form of the information in the original article. Characteristics of the study and applications are discussed.

in the 1930s (Nadler, 1998). Moreover, the long absence of comparable data from other groups of Caucasians has led to a de facto assumption of homogeneity in the growth tempo of contemporary humans. That is, since only the MFH data were available for decades, it was presumed that these standards were applicable globally. More recent studies of other groups has disclosed important systematic differences in the tempos of growth among populations (e.g., Fanning and Moorrees, 1969; Haavikko, 1970; Anderson et al., 1976; Harris and McKee, 1990; Liversidge and Molleson, 1999) as well as in the sequencing of tooth formation (Tompkins, 1996).

A technical difficulty in using the MFH data is that the information was only published in graphical format; there was no supporting table of descriptive statistics. This obliged users to plot each of their cases on a graph, which is tedious, impractical if sample sizes are large, and still required interpolation of the graph to a numerical value of "dental age." Also, the graphs cannot be used to computerize the methodology (cf. Demirjian et al., 1973).

The two-fold purpose of the present note is to supply tables of descriptive statistics for the MFH data and to comment on the nature and limitations of these classic data.

\section{MATERIALS AND METHODS}

Moorrees, Fanning and Hunt (1963) scored the formation of 10 teeth from oblique jaw radiographs. These were the maxillary incisors (I1, I2) and all eight mandibular tooth types (I1 through M3). The other maxillary teeth were excluded because superimposition of the complex bony structures of the midface interfered with their consistent visualization on the radiographs.

MFH combined two collections of growth data for their study. Children with chronological ages prior to about 10 years were obtained from headfilms that had

Correspondence to: E. F. Harris, Department Orthodontics, University of Tennessee, Memphis, TN 38163

E-mail: eharris@utmem.edu 
TABLE 1. Age at attainment (years) of stages of crown-root formation of permanent incisors ${ }^{1}$

\begin{tabular}{|c|c|c|c|c|c|c|c|c|}
\hline \multirow[b]{2}{*}{ Grade } & \multicolumn{2}{|c|}{ UI1 } & \multicolumn{2}{|c|}{ UI2 } & \multicolumn{2}{|c|}{ LI1 } & \multicolumn{2}{|c|}{ LI2 } \\
\hline & $\bar{x}$ & $\mathrm{sd}$ & $\bar{x}$ & $\mathrm{sd}$ & $\bar{x}$ & $\mathrm{sd}$ & $\bar{x}$ & $\mathrm{sd}$ \\
\hline \multicolumn{9}{|c|}{ Girls } \\
\hline $\mathrm{Ci}$ & • & • & • & • & • & • & • & • \\
\hline Cco & • & • & • & • & • & • & • & • \\
\hline Coc & • & $\bullet$ & $\bullet$ & • & • & • & • & • \\
\hline Cr $1 / 2$ & $\bullet$ & • & • & • & • & • & • & • \\
\hline Cr $2 / 3$ & • & • & 4.6 & 0.51 & • & $\bullet$ & • & • \\
\hline $\mathrm{Cr} 3 / 4$ & • & • & • & • & • & • & $\bullet$ & • \\
\hline $\mathrm{CrC}$ & 4.9 & 0.54 & 5.7 & 0.62 & • & • & $\bullet$ & • \\
\hline $\mathrm{R} 1 / 4$ & 6.0 & 0.66 & 6.6 & 0.71 & 4.5 & 0.51 & 4.7 & 0.53 \\
\hline R $1 / 3$ & • & • & - & - & - & - & 5.2 & 0.57 \\
\hline $\mathrm{R} 1 / 2$ & 6.6 & 0.71 & 7.2 & 0.76 & 5.1 & 0.57 & 5.9 & 0.65 \\
\hline R 2/3 & 7.1 & 0.76 & 7.7 & 0.82 & 5.6 & 0.62 & 6.3 & 0.68 \\
\hline R 3/4 & 7.6 & 0.81 & 8.3 & 0.87 & 6.1 & 0.66 & 6.7 & 0.72 \\
\hline R c & 8.2 & 0.86 & 9.1 & 0.95 & 6.6 & 0.72 & 7.6 & 0.80 \\
\hline A $1 / 2$ & 8.9 & 0.93 & 9.6 & 0.99 & 7.4 & 0.79 & 8.1 & 0.86 \\
\hline $\mathrm{Ac}^{\prime}$ & $\bullet$ & $\bullet$ & • & $\bullet$ & 7.7 & 0.82 & 8.5 & 0.89 \\
\hline \multicolumn{9}{|c|}{ Boys } \\
\hline $\mathrm{Ci}$ & - & - & - & - & • & • & • & • \\
\hline C co & • & - & - & - & • & - & - & - \\
\hline $\mathrm{C} \mathrm{OC}$ & • & - & - & - & • & - & • & - \\
\hline Cr $1 / 2$ & • & • & - & - & • & • & $\bullet$ & • \\
\hline $\mathrm{Cr} 3 / 4$ & • & - & - & - & • & - & - & - \\
\hline $\mathrm{Crc}$ & 5.3 & 0.59 & 5.9 & 0.64 & - & - & • & - \\
\hline R $1 / 4$ & 6.3 & 0.68 & 6.9 & 0.75 & • & - & 5.3 & 0.60 \\
\hline R $1 / 3$ & • & - & • & - & • & - & 5.6 & 0.62 \\
\hline $\mathrm{R} 1 / 2$ & 6.9 & 0.74 & 7.6 & 0.80 & 5.2 & 0.59 & 6.2 & 0.68 \\
\hline R 2/3 & 7.6 & 0.80 & 8.1 & 0.86 & 5.8 & 0.64 & 6.8 & 0.74 \\
\hline R 3/4 & 8.1 & 0.85 & 8.7 & 0.91 & 6.4 & 0.70 & 7.4 & 0.78 \\
\hline R c & 8.6 & 0.90 & 9.6 & 1.01 & 7.0 & 0.75 & 8.0 & 0.84 \\
\hline A $1 / 2$ & • & - & - & - & 7.7 & 0.81 & 8.5 & 0.90 \\
\hline Ac & - & - & - & - & 8.1 & 0.85 & 9.3 & 0.98 \\
\hline
\end{tabular}

${ }^{1}$ Codes: cusp (C), crown (Cr), root (R), apex (A). Stages: initiation (i), coalescence (co), cusp outline complete (co), complete (c), interradicular root cleft $(\mathrm{cl})$.

been collected at Harvard University by Harold C. Stuart (e.g., Stuart et al., 1939). World War II interrupted Stuart's collecting, so data also were obtained from the Fels Longitudinal Study in Yellow Springs, Ohio (Roche, 1992). The resulting set of data is somewhat confounded because information on younger and older children were obtained from different populations of "North American White children," and the Fels children had a faster tempo of growth (S. M. Garn, pers. comm.).

Both the Harvard and Fels data were collected in a longitudinal manner (Moorrees, 1959; Roche, 1992), which makes it curious that MFH used a graphical method of probit analysis (e.g., Finney, 1971) to calculate average ages at attainment of each tooth's stage of formation. This wastes the value of the longitudinal data because the onset of a stage can be identified directly from successive films, and it treats the data cross-sectionally if the ages of all children exhibiting a stage are averaged (Smith, 1991)

Besides the foldout graphs published in the Journal of Dental Research (MFH, 1963), these authors made copies available to the interested public in an oversize $11^{\prime \prime} \mathrm{x}$ $17^{\prime \prime}$ format. It was intended that a sheet be used once for a child then filed or discarded. We have used these oversize sheets to "reverse engineer" the process of obtaining numerical values from the graphs. Positions of the means and lengths of the error bars were obtained with drafting instruments and sliding calipers. Some researchers have estimated the means (but not the SD) from the MFH graphs (see, e.g., Ubelaker, 1999; Smith, 1991; Scheuer and Black, 2000), but inconsistencies in their data suggest that they used the smaller graphs in the Journal of Dental Research. We were able to base the data in our tables on more precise measurements. 


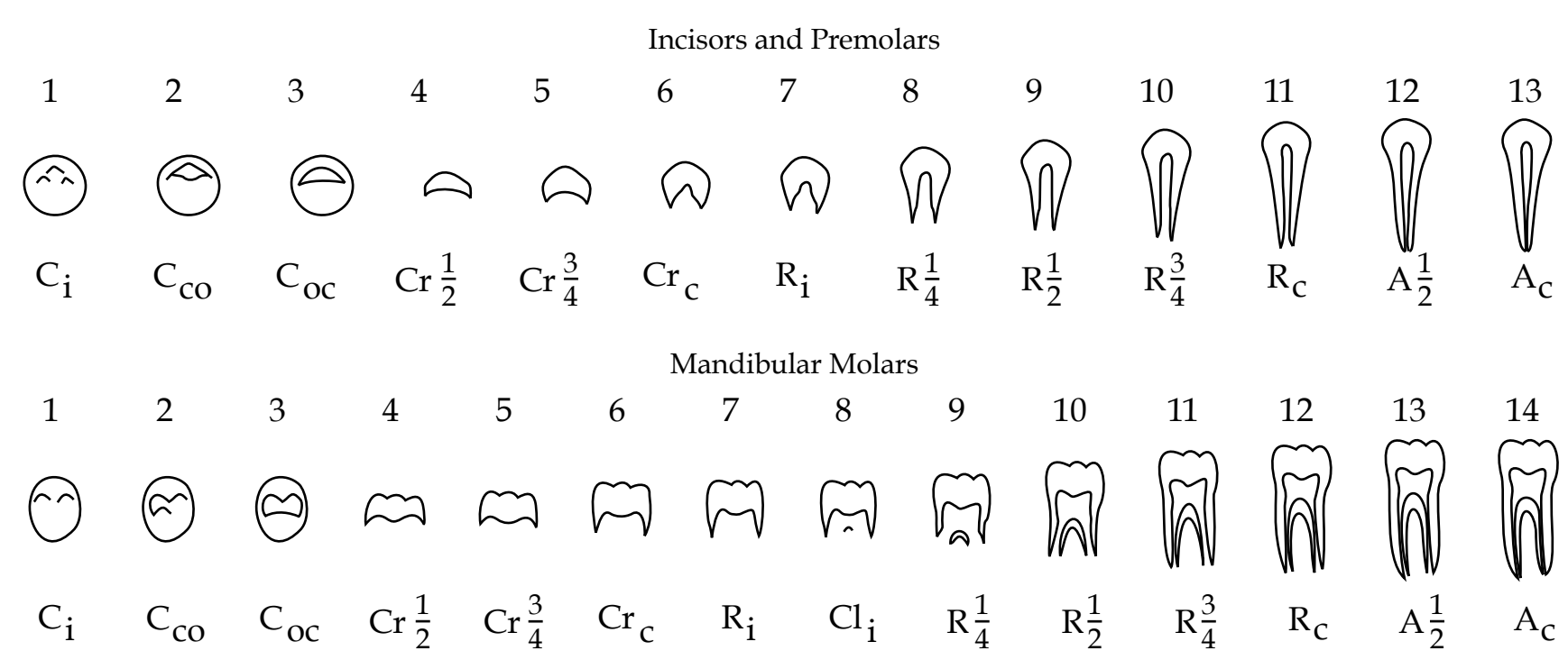

Fig. 1. Diagrammatic illustrations of the morphological grading system for crown-root mineralization of the singlerooted (top) and multi-rooted teeth (bottom). (Modified from Moorrees et al., 1963).

\section{RESULTS}

Means and standard deviations by tooth, grade, and sex are listed in Tables 1 and 2. The sample sizes of scorable teeth at each examination were not reported, but they could not have exceeded the 99 Boston children available up to about age 10 (48 boys; 51 girls) nor the 246 Fels children at later ages (136 boys; 110 girls).

According to their text, MFH scored the stages of crown-root formation using a 13-stage (single rooted teeth) or a 14-stage (multi-rooted teeth) scheme. These stages are illustrated in Figure 1 and defined in Table 3. The difference is simply that the initial mineralization of the interradicular (bifurcation) area is an additional stage for molars. The ordinal scale used by MFH was effectively the brain child of Izaac Gleiser and Edward Hunt (1955), also at the Forsyth Dental Infirmary, who previously had created a 15-grade scale to characterize development of the lower first molar. Elizabeth Fanning $(1958,1960,1961)$ elaborated this grading scheme to 20 stages for the molars (and 12 for incisors and 18 for premolars). These schemes, except for the incisors, proved to be too fine-grained, leading to confusion between nearly-identical adjacent grades, so MFH settled on a simpler system. The practical value of the resulting morphological criteria is reflected in its adoption in numerous subsequent studies (e.g., Haavikko, 1974; Demirjian et al., 1973; Anderson et al., 1976; Harris and McKee, 1990). Fanning actually scored the radiographs in the MFH study using more grades than illustrated in their article (see Fig. 1). This is obvious from the inclusion of "extra" grades in their diagrams (and see Table 1). For example, R 1/3 and R 2/3 are graphed for some teeth but not others and not included in the grades illustrated in their article. There also is the grade of $\mathrm{Cr}$ $2 / 3$ that is graphed only for the upper lateral incisor and only for girls, not boys. It seems to us that these "extra" grades were included when there was an adequate sample for statistical analysis, while the illustrations of the grades were made uniform across all tooth types for consistency.

\section{DISCUSSION}

How is dental age figured for a child? The MFH approach-which still is broadly applied-uses their graphs to determine the normative chronological ages at which the formative stage of each scorable tooth has been achieved, then these tooth-specific ages are averaged as the person's dental age. As an example, if the archeological remains of a girl are examined and UI1 and UC both have their root half-formed and the crown of UM2 is three-fourths complete, then the normative tooth specific dental ages are 6.6, 7.1, and 6.2 years, respectively (Tables $1-2$ ). The average dental age would be the arithmetic mean, 6.6 years.

The downside of this method is that the tempos of tooth formation are statistically interrelated (Moorrees and Kent, 1981; Anderson and Popovich, 1981), so there is some unknown redundancy in combining all teeth. This remains an ambiguous issue because the structure of tooth interrelationships has not been described in any detail, but it is evident that it varies among individuals and among populations (e.g., Tompkins, 1996). Some researchers have developed methods of dental aging based on fewer teeth (Haavikko, 1974; Bolanos et al., 2000), but these simplifications were driven by empirical assessments and on the ease of grading tooth stages - not on statistical criteria.

Demirjian and coworkers $(1973,1976)$ dealt with the issue of statistical interrelationships of formative rate among teeth by generating multiple linear regression equations that weighted each tooth's informational content. They also restricted the number of teeth since, again, intercorrelations are counter to the intuitive 
TABLE 2. Age at attainment of stages of crown-root formation for the permanent mandibular buccal teeth

\begin{tabular}{|c|c|c|c|c|c|c|c|c|c|c|c|c|}
\hline \multirow[b]{2}{*}{ Grade } & \multicolumn{2}{|c|}{ C } & \multicolumn{2}{|c|}{ P1 } & \multicolumn{2}{|c|}{ P2 } & \multicolumn{2}{|c|}{ M1 } & \multicolumn{2}{|c|}{ M2 } & \multicolumn{2}{|c|}{ M3 } \\
\hline & $\bar{x}$ & $\mathrm{sd}$ & $\bar{x}$ & sd & $\bar{x}$ & $\mathrm{sd}$ & $\overline{\mathbf{x}}$ & sd & $\bar{x}$ & $\mathrm{sd}$ & $\bar{x}$ & $\mathrm{sd}$ \\
\hline \multicolumn{13}{|c|}{ Girls } \\
\hline $\mathrm{Ci}$ & 0.5 & 0.12 & 1.7 & 0.24 & 2.9 & 0.35 & 0.1 & 0.05 & 3.5 & 0.41 & 9.6 & 1.00 \\
\hline C co & 0.7 & 0.15 & 2.2 & 0.28 & 3.5 & 0.40 & 0.2 & 0.09 & 3.8 & 0.43 & 10.1 & 1.05 \\
\hline C oc & 1.2 & 0.18 & 2.9 & 0.35 & 4.1 & 0.47 & 0.7 & 0.14 & 4.3 & 0.49 & 10.7 & 1.11 \\
\hline $\operatorname{Cr} 1 / 2$ & 1.9 & 0.25 & 3.5 & 0.41 & 4.7 & 0.53 & 1.0 & 0.17 & 4.8 & 0.54 & 11.3 & 1.17 \\
\hline $\mathrm{Cr} 3 / 4$ & 2.9 & 0.35 & 4.2 & 0.49 & 5.3 & 0.59 & 1.4 & 0.20 & 5.4 & 0.59 & 11.7 & 1.20 \\
\hline $\mathrm{CrC}$ & 3.9 & 0.45 & 5.0 & 0.56 & 6.2 & 0.66 & 2.2 & 0.28 & 6.2 & 0.68 & 12.3 & 1.27 \\
\hline $\mathrm{Ri}$ & 4.7 & 0.52 & 5.7 & 0.63 & 6.7 & 0.73 & 2.6 & 0.32 & 7.0 & 0.75 & 12.9 & 1.32 \\
\hline $\mathrm{R} \mathrm{cl}$ & - & & - & - & - & - & 3.5 & 0.41 & 7.8 & 0.83 & 13.5 & 1.39 \\
\hline R $1 / 4$ & 5.3 & 0.57 & 6.5 & 0.69 & 7.5 & 0.79 & 4.6 & 0.52 & 9.1 & 0.96 & 14.9 & 1.53 \\
\hline $\mathrm{R} 1 / 2$ & 7.1 & 0.75 & 8.1 & 0.86 & 8.7 & 0.92 & 5.1 & 0.57 & 9.8 & 1.01 & 15.8 & 1.62 \\
\hline R 3/4 & 8.3 & 0.88 & 8.8 & 0.97 & 10.0 & 1.05 & 5.5 & 0.60 & 10.5 & 1.09 & 16.4 & 1.67 \\
\hline $\mathrm{R}_{\mathrm{c}}$ & 8.8 & 0.93 & 9.9 & 1.03 & 10.6 & 1.12 & 5.9 & 0.63 & 11.0 & 1.13 & 17.0 & 1.71 \\
\hline A $1 / 2$ & 9.9 & 1.03 & 11.0 & 1.15 & 12.0 & 1.24 & 6.5 & 0.71 & 12.0 & 1.23 & 18.0 & 1.82 \\
\hline$A c$ & 11.3 & 1.18 & 12.1 & 1.26 & 13.6 & 1.40 & 8.0 & 0.85 & 13.8 & 1.43 & 20.1 & 2.01 \\
\hline \multicolumn{13}{|c|}{ Boys } \\
\hline $\mathrm{Ci}$ & 0.5 & 0.11 & 1.8 & 0.24 & 3.0 & 0.37 & 0.0 & 0.09 & 3.7 & 0.42 & 9.2 & 0.98 \\
\hline C co & 0.8 & 0.15 & 2.3 & 0.31 & 3.5 & 0.42 & 0.2 & 0.11 & 4.0 & 0.44 & 9.7 & 1.01 \\
\hline $\mathrm{Coc}$ & 1.2 & 0.19 & 2.9 & 0.36 & 4.2 & 0.48 & 0.5 & 0.11 & 4.8 & 0.52 & 10.3 & 1.07 \\
\hline $\operatorname{Cr} 1 / 2$ & 2.1 & 0.27 & 3.6 & 0.43 & 4.7 & 0.53 & 1.0 & 0.17 & 5.1 & 0.56 & 10.9 & 1.14 \\
\hline $\mathrm{Cr} 3 / 4$ & 2.9 & 0.35 & 4.4 & 0.52 & 5.3 & 0.59 & 1.5 & 0.21 & 5.7 & 0.61 & 11.6 & 1.20 \\
\hline $\mathrm{Crc}$ & 4.0 & 0.46 & 5.2 & 0.58 & 6.2 & 0.69 & 2.1 & 0.29 & 6.5 & 0.69 & 12.0 & 1.24 \\
\hline $\mathrm{Ri}$ & 4.8 & 0.55 & 5.8 & 0.64 & 6.9 & 0.74 & 2.7 & 0.34 & 7.1 & 0.76 & 12.7 & 1.32 \\
\hline $\mathrm{R} \mathrm{cl}$ & • & - & - & - & - & - & 3.5 & 0.41 & 8.1 & 0.84 & 13.6 & 1.41 \\
\hline R $1 / 4$ & 5.7 & 0.63 & 6.8 & 0.74 & 7.8 & 0.83 & 4.7 & 0.53 & 9.3 & 0.98 & 14.6 & 1.50 \\
\hline R $1 / 2$ & 8.0 & 0.86 & 8.5 & 0.91 & 9.4 & 0.99 & 5.1 & 0.57 & 10.1 & 1.04 & 15.1 & 1.54 \\
\hline R 3/4 & 9.6 & 1.00 & 9.9 & 1.04 & 10.8 & 1.13 & 5.4 & 0.61 & 10.8 & 1.12 & 15.9 & 1.62 \\
\hline R c & 10.2 & 1.06 & 10.3 & 1.09 & 11.5 & 1.21 & 5.8 & 0.64 & 11.3 & 1.16 & 16.3 & 1.67 \\
\hline A $1 / 2$ & 11.8 & 1.23 & 11.9 & 1.24 & 12.7 & 1.30 & 6.9 & 0.75 & 12.2 & 1.25 & 17.6 & 1.79 \\
\hline Ac & 13.0 & 1.35 & 13.3 & 1.38 & 14.2 & 1.46 & 8.5 & 0.91 & 14.2 & 1.46 & 19.2 & 1.95 \\
\hline
\end{tabular}

approach that more teeth should yield more information about a person's biological age.

We are unaware of any study that has made use of the standard deviations in the MFH article, presumably because there is no way of applying these measures of variation in their graphical form unless the chronological age is known - which often is not the case in archeological, forensic and some ethnological settings (e.g, Voors and Metselaar, 1958; Voors, 1973). Now that these values are tabled, they can be used to test for statistical significance, for an individual compared to the group or between the MFH sample and another sample. This can be done on a tooth-specific basis (averaging over individuals) or using the individual as the unit of study (averaging over tooth types) as described by Harris et al. (1993).

In sum, we have reverse-engineered the often-used graphs published by Moorrees, Fanning and Hunt (1963) to provide normative data on American white children for crown-root development of 10 permanent tooth types. The intent is to make these data-means and standard deviations-more usable in terms of statistical applications and computerization of the dental aging method.

\section{LITERATURE CITED}

Anderson DL, Popovich F. 1981. Association of relatively delayed emergence of mandibular molars with molar reduction and molar position. Am J Phys Anthropol 1981;54:369-376.

Anderson DL, Thompson GW, Popovich F. 1976. Age of attainment of mineralization stages of the permanent dentition. J Forensic Sci 21:191-200.

Bolanos MV, Manrique MC, Bolanos MJ, Briones MT. 2000. Approaches to chronological age assessment based on dental calcification. Forensic Sci Int 110: 97-106.

Conroy CC, Vannier MW. 1987. Dental development 
TABLE 3. Definitions of the tooth formation stages ${ }^{1}$

\begin{tabular}{|c|c|c|}
\hline $\begin{array}{c}\text { Single- } \\
\text { Rooted } \\
\text { Teeth }\end{array}$ & Definitions & $\begin{array}{c}\text { Multi- } \\
\text { Rooted } \\
\text { Teeth }\end{array}$ \\
\hline 1 & Initial cusp formation: amelogenesis has begun on the individual cusp tips. & 1 \\
\hline 2 & $\begin{array}{c}\text { Coalescence of cusps: centers of mineralization are merged but } \\
\text { the border is not everywhere radiodense }\end{array}$ & 2 \\
\hline 3 & Cusp outline complete: the coronal outline of the tooth is mineralized. & 3 \\
\hline 4 & $\begin{array}{l}\text { Crown } 1 / 2 \text { formed: amelogenesis has proceeded half way to the } \\
\text { crown-root as judged from morphology of the radiodense portion }\end{array}$ & 4 \\
\hline 5 & Crown $1 / 2$ complete & 5 \\
\hline 6 & $\begin{array}{c}\text { Crown complete: morphologically, all the crown has mineralized } \\
\text { but root formation has not begun. }\end{array}$ & 6 \\
\hline 7 & Initial root formation: there is a trace of root radiopacity below the crown outline. & 7 \\
\hline-- & Initial cleft formation: mineralization is evident in the interradicular area. & 8 \\
\hline 8 & $\begin{array}{c}\text { Root length } 1 / 4 \text { : the radiographic morphology of the root } \\
\text { is } 1 / 4 \text { its projected final size. }\end{array}$ & 9 \\
\hline 9 & Root length $1 / 2$ complete. & 10 \\
\hline 10 & Root length $3 / 4$ complete. & 11 \\
\hline 11 & Root length complete. & 12 \\
\hline 12 & $\begin{array}{l}\text { Apex half closed: the lateral borders of the root tip become convex } \\
\text { rather than tapered as earlier. }\end{array}$ & 13 \\
\hline 13 & $\begin{array}{c}\text { Apical closure complete: size of the apical foramen is reduced } \\
\text { to its mature size. }\end{array}$ & 14 \\
\hline
\end{tabular}

${ }^{1}$ Modified from Harris and McKee (1990).

of the Taung skull from computerized tomography. Nature 329:625-627.

Crossner CG, Mansfield L. 1983. Determination of dental age in adopted non-European children. Swed Dent J 7:1-10.

Demirjian A, Goldstein H, Tanner JM. 1973. A new system of dental age assessment. Hum Biol 45:211227.

Demirjian A, Goldstein H. 1976. New systems for dental maturity based on seven and four teeth. Ann Hum Biol 3:411-421.

Fanning EA. 1958. A longitudinal study of tooth formation and root resorption. D.D.S. Thesis, University of New Zealand, 1960.

Fanning EA. 1960. A longitudinal study of tooth formation and root resorption. D.D.S. thesis, University of New Zealand.

Fanning EA. 1961. A longitudinal study of tooth formation and root resorption. NZ Dent J 57:202217.
Fanning EA, Moorrees CF. 1969. A comparison of permanent mandibular molar formation in Australian aborigines and Caucasoids. Arch Oral Biol 14:999-1006.

Finney DJ. 1971. Probit analysis, 3rd ed. New York: Cambridge University Press.

Garn SM. 1992. personal communication.

Garn SM, Lewis AB, Blizzard RM. 1965. Endocrine factors in dental development. J Dent Res 44:243258.

Gleiser I, Hunt Jr EE. 1955 The permanent mandibular first molar: its calcification, eruption and decay. Am J Phys Anthropol 13:253-281.

Haavikko K. 1970. The formation and the alveolar and clinical eruption of the permanent teeth: an orthopantomographic study. Proc Finn Dent Soc 66: 103-170.

Haavikko K. 1974. Tooth formation age estimated on a few selected teeth: a simple method for clinical use. Proc Finn Dent Soc 70:15-19. 
Harris EF. 2002. Dental development and anomalies in craniosynostosis and facial clefting. In: Mooney MP, Siegel MI, editors Understanding craniofacial anomalies: the etiopathogenesis of craniosynostosis and facial clefting. New York: John Wiley-Liss, p 425-467.

Harris EF, Barcroft BD, Haydar S, Haydar B. 1993. Delayed tooth formation in low birthweight American Black children. Pediatr Dent 15:30-35.

Harris EF, McKee JH. 1990. Tooth mineralization standards for blacks and whites from the middle southern United States. J Forensic Sci 35;859-872.

Keller EE, Sather AH, Hayles AB. 1970. Dental and skeletal development in various endocrine and metabolic disease. J Am Dent Assoc 81:415-419.

Kent RL Jr, Reed RB, Moorrees CF. 1978. Associations in emergence age among permanent teeth. Am J Phys Anthropol 48:131-142.

Liversidge HM. 2000. Crown formation times of human permanent anterior teeth. Arch Oral Biol 45:713-721.

Liversidge HM, Molleson TI. 1999. Developing permanent tooth length as an estimate of age. J Forensic Sci 44:917-920.

Marshall WA, Tanner JM. 1969. Variations in pattern of pubertal changes in girls. Arch Dis Child 44:291-303.

Marshall WA, Tanner JM. 1970. Variations in pattern of pubertal changes in boys. Arch Dis Child 45:13-23.

Merwin DR, Harris EF. 1998. Sibling similarities in the tempo of tooth mineralization. Arch Oral Biol 43: 205-210.

Moorrees CFA. 1959. The dentition of the growing child. Cambridge: Harvard University Press.

Moorrees CFA, Fanning EA, Hunt Jr EE. 1963. Age variation of formation stages in ten permanent teeth. J Dent Res 42:1490-1502.

Moorrees CFA, Kent Jr RL. 1981. Interrelations in the timing of root formation and tooth emergence. Proc Finn Dent Soc 77:113-117.

Nadler GL. 1998. Earlier dental maturation: fact or fiction. Angle Orthod 68:535-538.

Owsley DW, Jantz RL. 1983. Formation of the permanent dentition in Arikara Indians: timing differences that affect dental age assessments. Am J Phys Anthropol 61:467-471.
Pelsmaekers B, Loos R, Carels C, Derom C, Vlietinck R. 1997. The genetic contribution to dental maturation. J Dent Res 76:1337-1340.

Roche AF. 1992. Growth, maturation, and body composition: the Fels Longitudinal Study 1929-1991. Cambridge: Cambridge University Press.

Scheuer L, Black S. 2000. Developmental Juvenile Osteology. San Diego: Academic Press.

Smith BH. 1991. Standards of human tooth formation and dental age assessment. In: Kelley MA, Larsen SP, editors. Advances in dental anthropology. New York: Wiley-Liss, p 143-168.

Stuart HC. 1939. Studies fromthe Center for Research in Child Health and Development, School of Public Health, Harvard University. I. The center, the group under observation, sources of information, and studies in progress. Monogr Soc for Research Child Devel, series no. 20, p 1-261.

Tanner JM, Whitehouse RH, Marshall WA, Healy MJR, Goldstein H. 1975. Assessment of skeletal maturity and prediction of adult height: TW2 method. London: Academic Press.

Tompkins RL. 1996. Human population variability in relative dental development. Am J Phys Anthropol 99:79-102.

Ubelaker DH. 1999. Human skeletal remains: excavation, analysis, interpretation, 3rd ed. Washington: Taraxacum.

Voors AW. 1973. Can dental development be used for assessing age in underdeveloped communities? J Trop Pediatr Environ Child Health 19:242.

Voors AW, Metselaar D. 1958. The reliability of dental age as a yardstick to assess the unknown calendar age. Trop Geogr Med 10:175-180.

\section{Decoding Your Subscription}

Want to know when your subscription to Dental Anthropology expires? Membership in the Association and, thus, your subscription to Dental Anthropology is on an annual basis coinciding with the calendar year. Have a look at the mailing label on the evelope that this issue arrived in, and you will see the year for which your dues have been paid. The year is located in parentheses to the right of your name. So, if the mailing label says "(2002)" you are paid to the end of this calendar year.

In order to extend your membership, fill-out the relevant portions of the enclosed form-remember to include appropriate payment-and mail it to the Secretary-Treasurer of the Association:

Dr. Diane Hawkey

Department of Anthropology

Arizona State University

Tempe, Arizona 85287-2402 USA

e-mail: hawkey@asu.edu 